\title{
Visible Light-Mediated Sustainable Antibacterial Activity and Osteogenic Functionality of Au and Pt Multi-Coated $\mathrm{TiO}_{2}$ Nanotubes
}

\author{
Kyoung-Suk Moon ${ }^{1}$, Young-Bum Park ${ }^{2} \mathbb{D}$, Ji-Myung Bae $^{1}\left(\mathbb{D}\right.$, Eun-Joo Choi $^{3, *}$ and Seung-Han Oh ${ }^{1, *(D)}$ \\ 1 Department of Dental Biomaterials, The Institute of Biomaterial and Implant, School of Dentistry, Wonkwang \\ University, Iksan 54538, Korea; ksemoon@hanmail.net (K.-S.M.); baejimy@wku.ac.kr (J.-M.B.) \\ 2 Department of Prosthodontics, School of Dentistry, Yonsei University, Seoul 03722, Korea; drybpark@yuhs.ac \\ 3 Department of Oral and Maxillofacial Surgery, School of Dentistry, Wonkwang University, Iksan 54538, Korea \\ * Correspondence: cejoms@wku.ac.kr (E.-J.C.); shoh@wku.ac.kr (S.-H.O.); Tel.: +82-63-850-6931 (E.-J.C.); \\ $+82-63-850-6982$ (S.-H.O.)
}

check for

updates

Citation: Moon, K.-S.; Park, Y.-B.;

Bae, J.-M.; Choi, E.-J.; Oh, S.-H.

Visible Light-Mediated Sustainable

Antibacterial Activity and Osteogenic

Functionality of $\mathrm{Au}$ and $\mathrm{Pt}$

Multi-Coated $\mathrm{TiO}_{2}$ Nanotubes.

Materials 2021, 14, 5976. https://

doi.org/10.3390/ma14205976

Academic Editors: Tae-Yub Kwon and Du-Hyeong Lee

Received: 30 August 2021

Accepted: 7 October 2021

Published: 11 October 2021

Publisher's Note: MDPI stays neutral with regard to jurisdictional claims in published maps and institutional affiliations.

Copyright: (C) 2021 by the authors. Licensee MDPI, Basel, Switzerland. This article is an open access article distributed under the terms and conditions of the Creative Commons Attribution (CC BY) license (https:/ / creativecommons.org/licenses/by/ $4.0 /)$.

\begin{abstract}
The visible light reactions of noble metal-based photocatalysts have been increasingly utilized to investigate their antibacterial activities. Furthermore, the photoreactions at various visible light wavelengths for specific combinations of titania nanotubes and noble metal nanoparticles have been found to promote osteogenic functionality. In this investigation, a novel multi-coating combination of noble metals (gold and platinum) on titania nanotubes was assessed using plasmonic photocatalysis and low-level laser therapy at 470 and $600 \mathrm{~nm}$. The results showed that this coating on the nanotubes promoted antibacterial activity and osteogenic functionality. The order in which the gold and platinum coatings were layered onto the titania nanotubes strongly affected the osteogenic performance of the human mesenchymal stem cells. These results have identified a new approach for the development of efficient novel combinations of noble metal nanoparticles and titania nanotubes with visible light responses, sustainable antimicrobial activity, and osteogenic functionality.
\end{abstract}

Keywords: gold; platinum; multi-coating; titania nanotubes; visible light; antimicrobial activity; osteogenic functionality

\section{Introduction}

Ideal implant success in dentistry occurs when there is stable functionality of the dental prosthesis, which results from a strong bonding force based on high-quality osseointegration without infection in the region of the peri-implant soft tissue. If there is total implant failure, the desired function and aesthetics are not achieved, for mechanical or biological reasons [1,2]. Implant failure can be classified as early, which occurs during the initial loading period, or delayed, which occurs after the osseointegration process has been completed and implant function is achieved. Bacterial infection is one of the factors that cause early failure and may occur due to contamination of the implant itself, infection during surgery, or improper healing [3].

To improve the limitations of conventional antibacterial treatment methods such as a direct injection of antibacterial drugs, new technologies such as antimicrobial biomolecules [4-6], antibacterial nanoparticles [7-9], photodynamic therapy [10-12], and photocatalytic therapy [13-15] have been introduced. Among these, titania $\left(\mathrm{TiO}_{2}\right)$ based photocatalytic antibacterial treatments are predicted to be useful for dental and medical implants based on titania or titania alloys.

However, titania has the limitation of expressing a photocatalytic effect in the ultraviolet region due to its high bandgap energy. Many studies have attempted to address this limitation by expanding the photocatalytic effects to the visible light region [16-18]. Localized surface plasmon resonance (LSPR) related to the plasmonic photocatalyst generated 
by the combination of noble metals and titania is expected to be safe for use in implant surface treatment due to its excellent levels of biocompatibility [19-21].

In previous studies, we have developed $\mathrm{Au}$ and $\mathrm{Pt}$ single-coated $\mathrm{TiO}_{2}$ nanotubes showing visible light photocatalytic activity and osteogenic acceleration with selective visible light irradiation [22-24]. This research also showed that the resulting species of noble metal nanoparticles affected the antibacterial activity and osteogenic performance and were the basis for further investigations into variable factors such as species, morphology, and the coating conditions of the noble metal nanoparticles. Based on these factors, the multi-coating of noble metal nanoparticles is expected to double its properties and strongly express the bandgap features of each metal. Furthermore, previous studies related to $\mathrm{Au}$ and $\mathrm{Pt}$ bimetallic nanoparticles reported that $\mathrm{Pt}$ nanoparticles prevent the coarsening of Au nanoparticles, thereby exhibiting an improved and stable plasmonic photocatalytic effect $[25,26]$.

In this study, we prepared $\mathrm{Au}$ and $\mathrm{Pt}$ multi-coated $\mathrm{TiO}_{2}$ nanotubes and estimated the effect of the stacking sequence of $\mathrm{Au}$ and $\mathrm{Pt}$ on the antibacterial activity based on plasmonic photocatalysis and the osteogenic capability of the $\mathrm{Au}$ and $\mathrm{Pt}$ multi-coated $\mathrm{TiO}_{2}$ nanotubes under in vitro conditions. We also evaluated the osteogenic performance of Pt-coated $\mathrm{TiO}_{2}$ nanotubes showing excellent osteogenic function in a previous study and $\mathrm{Au}$ and $\mathrm{Pt}$ multi-coated $\mathrm{TiO}_{2}$ nanotubes.

\section{Materials and Methods}

\subsection{Preparation of $\mathrm{Au}$ and Pt Multi-Coated $\mathrm{TiO}_{2}$ Nanotubes}

The procedure, materials, and reagents for preparing anatase crystalline phased $\mathrm{TiO}_{2}$ nanotubes with diameters of $100 \mathrm{~nm}$ are the same as our previous research [24]. The specimen for the anodization process was $5 \times 5 \mathrm{~cm}^{2}$ and was cut to the size of $1 \times 1 \mathrm{~cm}^{2}$ to perform noble metal coating and in vitro experiments. $\mathrm{Au}$ and $\mathrm{Pt}$ multi-coatings were applied to the $\mathrm{TiO}_{2}$ nanotubes using an ion plasma sputter (E-1030; Hitachi Co., Tokyo, Japan).

For this investigation, we designated $\mathrm{AuPt}-\mathrm{TiO}_{2}$ nanotubes (condition for the first coating of $\mathrm{Au}$ and the second coating of $\mathrm{Pt}$ ) and $\mathrm{PtAu}-\mathrm{TiO}_{2}$ nanotubes (condition for the first coating of $\mathrm{Pt}$ and the second coating of $\mathrm{Au}$ ) according to the coating sequence of the $\mathrm{Au}$ and $\mathrm{Pt}$ on the $\mathrm{TiO}_{2}$ nanotubes. The coating time of $\mathrm{Au}$ and $\mathrm{Pt}$ were 30 and $60 \mathrm{~s}$, respectively. $\mathrm{TiO}_{2}$ nanotubes without noble metal coating were used as a control.

\subsection{Surface Characteristics}

The equipment and measurement methods such as field-emission scanning electron microscope (FE-SEM; S4800S; Hitachi \& Horiba Co., Tokyo, Japan), transmission electron microscope (TEM; JEM-ARM200F; JEOL Co., Tokyo, Japan), and diffuse reflectance UVVis-NIR spectrophotometer (SolidSpec-3700; Shimadzu Co., Tokyo, Japan) used in this study for the surface characterization of the $\mathrm{Au}$ and $\mathrm{Pt}$ multi-coated $\mathrm{TiO}_{2}$ nanotubes are the same as in our previous study [24]. The X-ray photoelectron spectroscopy (XPS; K-Alpha; Thermo Fisher Scientific Inc., Waltham, MA, USA) was equipped with a monochromatic A1 $\mathrm{K} \alpha$ source. From the FE-SEM images, the diameter of forty nanoparticles coated on the $\mathrm{TiO}_{2}$ nanotubes was measured using Image J software (Version 1.53b, NIH, Bethesda, MD, USA) to evaluate the size distribution of deposited nanoparticles.

\subsection{Antibacterial Activity Test}

The experimental conditions and procedures of the antibacterial activity test are the same as those of our previous study except for the period of visible light irradiation [24]. We used Staphylococcus aureus (S. aureus; ATCC 25923, Manassas, VA, USA) to perform the antibacterial activity test. All specimens in this experiment were autoclaved at $120^{\circ} \mathrm{C}$ for $10 \mathrm{~min}$. We performed visible light irradiation on the S. aureus for 15 min using a lab-fabricated 470 and $600 \mathrm{~nm}$ visible light-emitting diode (LED) device (Power density $=5.5 \mathrm{~mW} / \mathrm{cm}^{2}$, the distance between the specimen and the LED device $=2 \mathrm{~cm}$ ). After light irradiation, we collected $100 \mu \mathrm{L}$ bacteria from the specimen by sonication for 
5 min (SH-2100; Saehan Ultrasonic Co., Seoul, Korea). The dilution concentration of the collected bacteria was adjusted by adding PBS solution. One hundred microliters of the diluted bacteria were seeded on an agar layer in a $100 \mathrm{~mm}$ cell culture dish. After $24 \mathrm{~h}$ of additional incubation, the value of the antibacterial activity is expressed by multiplying the number of attached bacteria by the dilution index. Compared with a previous study [24], the irradiation time was reduced from 30 to $15 \mathrm{~min}$ to prevent unwanted bacteria death due to drying the agar culturing the bacteria during a long irradiation time. To minimize the side effect of unwanted light irradiation, all samples were placed in the dark during the entire experimental period.

\subsection{Human Mesenchymal Stem Cell Cultures}

The cell culture conditions, growth media, and osteogenic differentiation media of human mesenchymal stem cells (hMSCs; Lonza Co., Basel, Switzerland) used in this study are the same as in our previous study [24]. The cultured hMSCs were washed by phosphate buffer solution (PBS; Invitrogen Co., Waltham, MA, USA) and replaced with fresh media every 3 days.

\subsection{Alkaline Phosphatase (ALP) Activity Assay}

The ALP activity assay was performed by ALP colorimetric assay kit (K412; Biovision Inc., Milpitas, CA, USA) composed of ALP assay buffer, $5 \mathrm{mM}$ para-nitrophenyl phosphate (p-NPP), ALP enzyme, and stop solution. We used a 24-well plate to place the specimen and seeded 20,000 cells of hMSCs onto each well. After $1 \mathrm{~h}$ of incubation, we performed 1st visible light irradiation on the hMSCs for 30 min using lab-fabricated visible light LED device. Further visible light irradiations were conducted after changing the osteogenic media every 3 days. After 1 and 2 weeks of cell culture, the hMSCs were collected and lysed in a $200 \mu \mathrm{L}$ of Assay buffer solution. After 30 min of lysis, $50 \mu \mathrm{L}$ of $5 \mathrm{mM}$ p-NPP solution was added to $80 \mu \mathrm{L}$ cell lysate and reacted at $37^{\circ} \mathrm{C}$ for $30 \mathrm{~min}$. Then, $20 \mu \mathrm{L}$ of stop solution was added to the reaction solution to stop the p-NPP reaction. The absorbance value of the final solution was measured by the microplate ELISA reader (SpectroMax 250; Thermo Electron Co., Waltham, MA, USA) at $405 \mathrm{~nm}$ wavelength. The value of ALP activity was calculated by dividing the absorbance value of each sample by the total protein amount of each sample. The quantification of proteins was conducted by Pierce ${ }^{\mathrm{TM}} \mathrm{BCA}$ Protein Assay Kit (Thermo Fisher Scientific Inc., Waltham, MA, USA). To minimize the experimental errors, three specimens were combined at once to make one sample. The number of samples for statistical analysis was four.

\section{6. hMSC Morphological Changes under Visible Light Irradiation}

The filopodia behavior of the hMSCs cultured on the experimental specimen after visible light irradiation was observed by FE-SEM. We used a 24-well plate to place the specimen and seeded 5000 cells of hMSCs onto each well. After $24 \mathrm{~h}$ of cell culture, we irradiated 470 and $600 \mathrm{~nm}$ visible light onto the specimen for $30 \mathrm{~min}$. The procedure and reagents for fixing, dehydrating, and drying the hMSCs cultured on the specimen are the same as in our previous study [24]. The micromorphological changes of the hMSCs were checked by FE-SEM.

\subsection{Quantitative Real-Time PCR Assay}

The real-time PCR assay equipment, experimental procedures, reagents, and the TaqMan ${ }^{\circledR P C R}$ primers (GAPDH, OPN, and BSP) used in this study are the same as in the previous study [24]. In addition, the TaqMan®PCR primer for OCN (Hs01587813_g1, Amplicon length: 166) was also used to analyze the osteocalcin gene expression. The culture procedure of the hMSCs and visible light irradiation conditions for the quantitative real-time PCR assay were the same as those for the ALP activity assay. In brief, after 1 and 2 weeks of cell culture, the total RNA was extracted from the hMSCs and reversetranscribed into cDNA. The expressions of interest genes and GAPDH (house-keeping gene) 
were obtained from real-time PCR assay using $1 \mu \mathrm{L}$ cDNA. To minimize the experimental errors, three specimens were combined at once to make one sample. The number of samples for statistical analysis was six.

\subsection{Alizarin Red Assay}

The culture procedure for the hMSCs and visible light irradiation conditions for the alizarin red assay were the same as those for the ALP activity assay. After 2 and 3 weeks of cell culture, the specimen was rinsed with PBS solution and fixed with $4 \%$ paraformaldehyde solution (Sigma-Aldrich Co., St. Louis, MO, USA) at $25^{\circ} \mathrm{C}$ for $20 \mathrm{~min}$. The fixed specimen was then stained with alizarin red solution (Sigma) for $20 \mathrm{~min}$. The stained specimen was washed with de-ionized water and reacted with $10 \%$ acetic acid (JT Baker Co., Phillipsburg, NJ, USA) for $30 \mathrm{~min}$. The reacted specimen was stored at $85^{\circ} \mathrm{C}$ for $10 \mathrm{~min}$. The supernatant was then collected from the specimen after the centrifugation (11,000 rpm for 15 min: Micro 17TR, Hanil Co., Daejeon, Korea). Neutralization was performed by adding the same volume of $10 \%$ ammonium hydroxide (Sigma-Aldrich Co., St. Louis, MO, USA) to the supernatant. The absorbance value of the neutralized supernatant was measured at $405 \mathrm{~nm}$ with a microplate ELISA reader. To minimize the experimental errors, three specimens were combined at once to make one sample. The number of samples used in the statistical analysis is three.

\subsection{Statistical Analysis}

All data obtained by conducting this study were expressed as means standard deviations. Data analysis was performed by one-way analysis of variance (one-way ANOVA; IBM SPSS Statistics 24.0; IBM, Armonk, NY, USA) and Duncan's multiple range test as a post hoc. A $p$-value less than 0.05 is statistically significant.

\section{Results}

\subsection{Surface Characteristics \\ 3.1.1. FE-SEM Observation}

The FE-SEM images for the AuPt- $\mathrm{TiO}_{2}$ nanotubes and $\mathrm{PtAu}-\mathrm{TiO}_{2}$ nanotubes after 30 and $60 \mathrm{~s}$ of plasma coating are shown in Figure 1. There were no significant changes in the morphology of the surface layer regardless of the stacking order of the $\mathrm{Au}$ and $\mathrm{Pt}$. However, the large agglomeration of the nanoparticles was observed in the experimental group coated for $60 \mathrm{~s}$. The average diameter of the $\mathrm{AuPt}-\mathrm{TiO}_{2}$ nanotubes and $\mathrm{PtAu}-\mathrm{TiO}_{2}$ nanotubes for $30 \mathrm{~s}$ coating was $9.89 \pm 1.68$ and $12.76 \pm 2.91 \mathrm{~nm}$, and when coated for $60 \mathrm{~s}$ it was $21.32 \pm 4.27$ and $19.93 \pm 3.80 \mathrm{~nm}$, respectively.

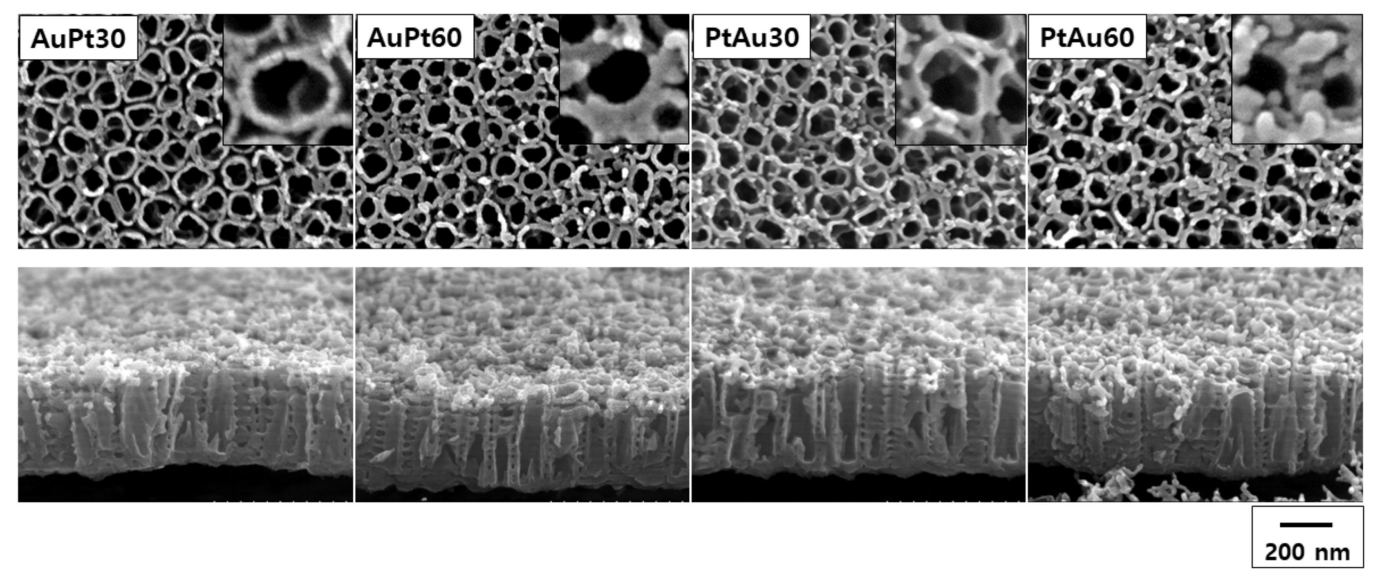

Figure 1. FE-SEM characterization of $\mathrm{AuPt}-\mathrm{TiO}_{2}$ nanotubes and $\mathrm{PtAu}-\mathrm{TiO}_{2}$ nanotubes $(\mathrm{AuPt} 30$ and AuPt60; 30 and $60 \mathrm{~s}$ of Au and Pt sputtering in this order, PtAu30 and PtAu60; 30 and $60 \mathrm{~s}$ of Pt and Au sputtering in this order, respectively) (top: plain view, bottom: oblique view, inset: magnified plain view). 


\subsubsection{Diffuse Reflectance UV-Vis-NIR Spectrophotometry}

UV-Vis-NIR diffuse reflectance spectrophotometric curves for the AuPt-TiO ${ }_{2}$ nanotubes and $\mathrm{PtAu}-\mathrm{TiO}_{2}$ nanotubes are shown in Figure 2. The four major absorption spectra of the AuPt-TiO 2 nanotubes and $\mathrm{PtAu}-\mathrm{TiO}_{2}$ nanotubes were all found within the following wavelengths: $360-380,420-480,550-650$, and $800-950 \mathrm{~nm}$. Two peaks at $420-480$ and 550-650 nm follow the LSPR based plasmonic photocatalysis and the photothermal scattering of $\mathrm{Au}$ and $\mathrm{Pt}$ multi-coated on $\mathrm{TiO}_{2}$ nanotubes, respectively [27]. Additionally, from the UV-Vis-NIR diffusion reflectance spectrophotometric results, there was no difference according to the stacking sequence of the Au and Pt coating. From the FE-SEM observations and diffuse reflectance UV-Vis-NIR spectra results, the $\mathrm{Au}$ and $\mathrm{Pt}$ coating time of $30 \mathrm{~s}$ was selected for other experiments to prevent the coarsening and agglomeration of the deposited nanoparticles and to optimize the experimental process for the visible light-mediated sustainable antibacterial activity and osteogenic differentiation.

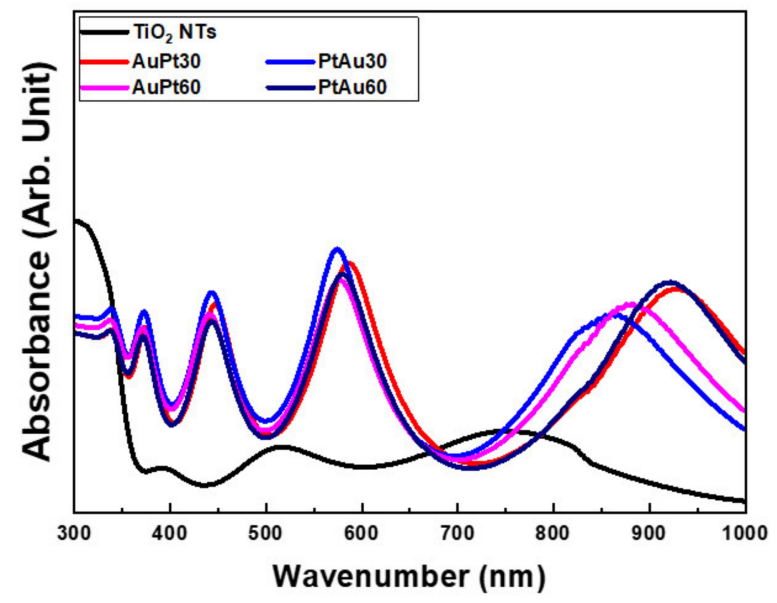

Figure 2. UV-Vis-NIR diffuse reflectance spectrophotometric curves for AuPt- $\mathrm{TiO}_{2}$ nanotubes and $\mathrm{PtAu}-\mathrm{TiO}_{2}$ nanotubes after various sputtering periods (AuPt30 and AuPt60; 30 and $60 \mathrm{~s}$ of Au and Pt sputtering in this order, PtAu30 and PtAu60; 30 and $60 \mathrm{~s}$ of Pt and Au sputtering in this order, respectively).

\subsubsection{TEM Observation and Elementary Analysis}

TEM images of AuPt-TiO $\mathrm{O}_{2}$ nanotubes and $\mathrm{PtAu}-\mathrm{TiO}_{2}$ nanotubes are shown in Figure 3. From the elementary mapping of the TEM images, most of the $\mathrm{Au}$ and $\mathrm{Pt}$ nanoparticles were distributed on the upper layer of the $\mathrm{TiO}_{2}$ nanotubes. Additionally, 2.20 and $1.69 \mathrm{wt} \%$ of the Pt and 4.65 and $5.39 \mathrm{wt} \%$ of the Au were detected in the mapped area of the $\mathrm{AuPt}-\mathrm{TiO}_{2}$ nanotubes and $\mathrm{PtAu}-\mathrm{TiO}_{2}$ nanotubes, respectively.

\section{(a) AuPt30}

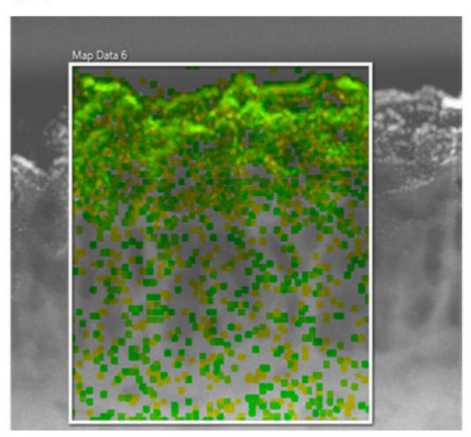

Pt Au

\section{(b) PtAu30}
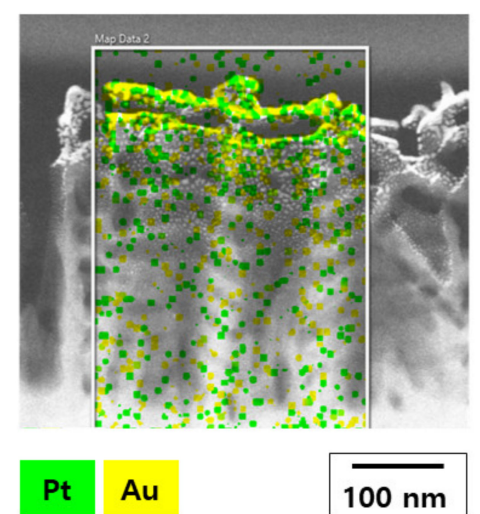

$100 \mathrm{~nm}$

Figure 3. TEM characterization of (a) $\mathrm{AuPt}-\mathrm{TiO}_{2}$ nanotubes (AuPt30) and (b) $\mathrm{PtAu}-\mathrm{TiO}_{2}$ nanotubes $(\mathrm{PtAu} 30)$. 


\subsubsection{XPS Analysis}

The XPS spectra for the AuPt-TiO ${ }_{2}$ nanotubes and $\mathrm{PtAu}-\mathrm{TiO}_{2}$ nanotubes are illustrated in Figure 4. The lower shift in the binding energy of the major peaks of Ti $2 p$ and $\mathrm{O} 1 \mathrm{~s}$ was caused by the decrease in $\mathrm{Ti}$ and $\mathrm{O}$ species following the coating of $\mathrm{Au}$ and Pt nanoparticles at the top surface of the $\mathrm{TiO}_{2}$ nanotubes. Moreover, a new peak at $72.5 \mathrm{eV}$ was detected in the $\mathrm{Pt} 4 \mathrm{f}$ spectra of the PtAu30. This peak seemed to be the formation of $\mathrm{Pt}-\mathrm{O}$ bonds when a small amount of $\mathrm{Pt}$ was first coated at the surface of the $\mathrm{TiO}_{2}$ nanotubes $[28,29]$.
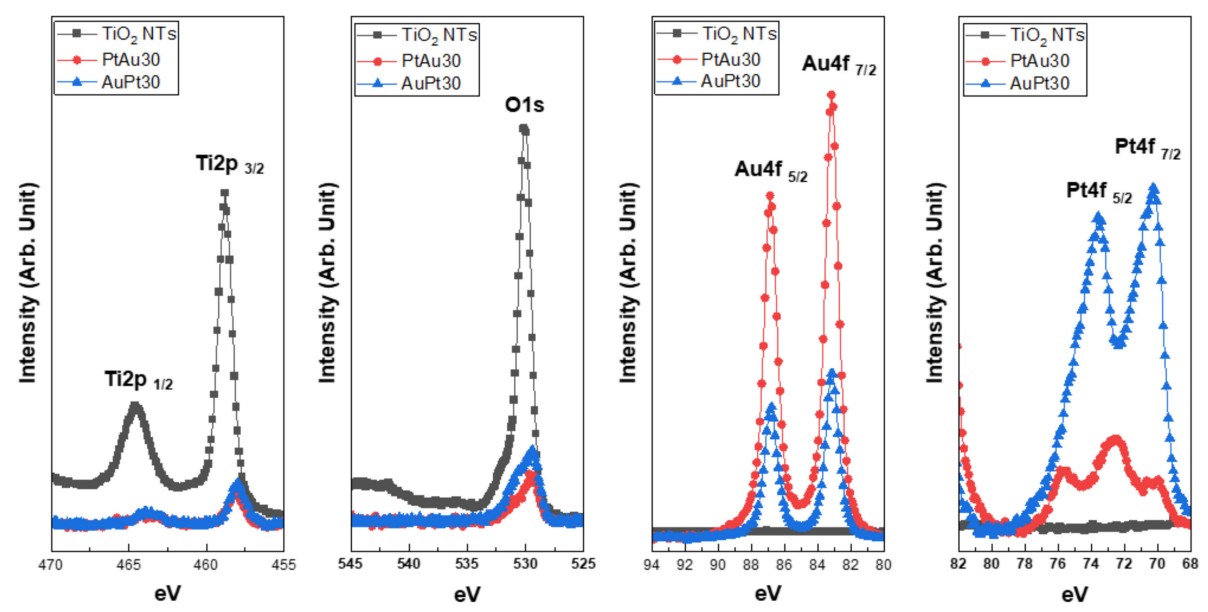

Figure 4. Ti 2p, O 1s, Au 4f, and Pt 4f XPS spectra of Au and Pt multi-coated $\mathrm{TiO}_{2}$ nanotubes.

\subsection{Antibacterial Activity Test}

In Figure 5, the $\mathrm{CFU}$ values of the $\mathrm{Au}$ and $\mathrm{Pt}$ multi-coated $\mathrm{TiO}_{2}$ nanotubes with 470 and $600 \mathrm{~nm}$ of visible light irradiation were significantly lower than those without visible light irradiation $(p<0.05)$. This result means that the combination of $\mathrm{Au}$ and $\mathrm{Pt}$ multi-coated $\mathrm{TiO}_{2}$ nanotubes and visible light irradiation showed antibacterial activity.

(a)

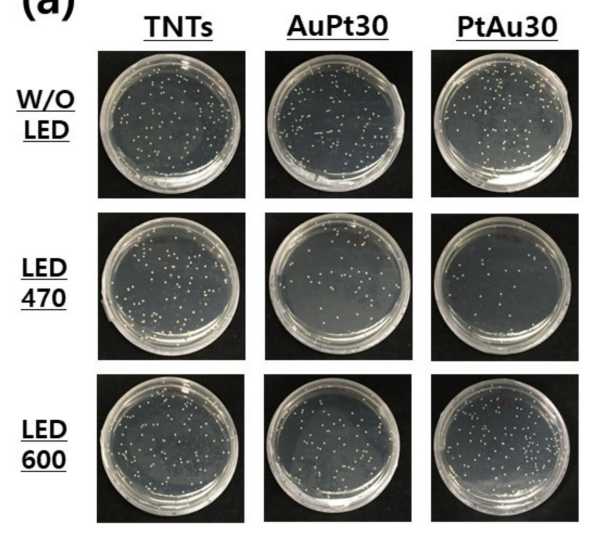

(b)

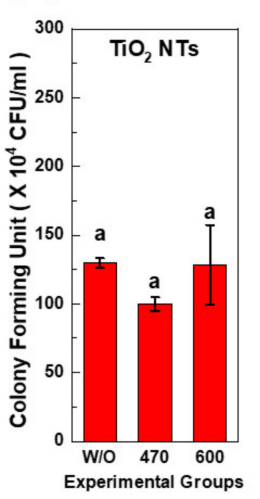

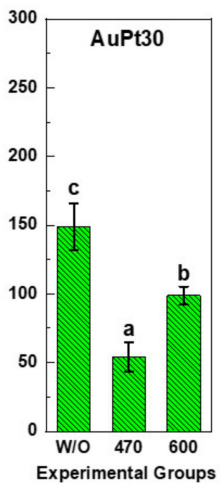

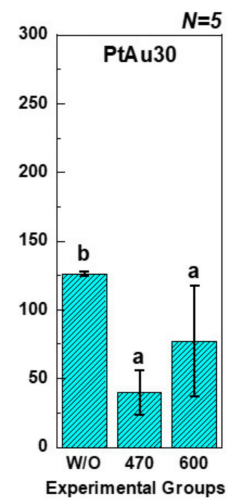

Figure 5. (a) Photo images of agar-based antibacterial activity test and (b) CFU values per unit volume of $S$. aureus. In the graph, W/O, 470, and 600 designate no irradiation, $470 \mathrm{~nm}$ irradiation, and $600 \mathrm{~nm}$ irradiation, respectively. Moreover, in each graph, the values of experimental groups with the same lowercase letter $(a, b$, or $c)$ are not statistically different as determined by one-way ANOVA at $\alpha=0.05$.

\subsection{Biocompatibility and Osteogenic Functionality of hMSCs}

\subsection{1. hMSCs Morphological Observation by FE-SEM}

The FE-SEM images $(100 \times$ and $50,000 \times)$ of the hMSCs cultured on $\mathrm{Au}$ and Pt multicoated $\mathrm{TiO}_{2}$ nanotubes with or without visible light irradiation (470 and $600 \mathrm{~nm}$ for $30 \mathrm{~min}$ ) are shown in Figure 6. Many filopodia and spreading of the hMSCs were found in the 
experimental group irradiated with $600 \mathrm{~nm}$ light (Figure 6a). In Figure 6b, the filopodia of the hMSCs were detached from the surface with $470 \mathrm{~nm}$ light irradiation. However, the hMSCs irradiated with $600 \mathrm{~nm}$ light adhered well to the specimen surface and showed elongated filopodia.

(a)

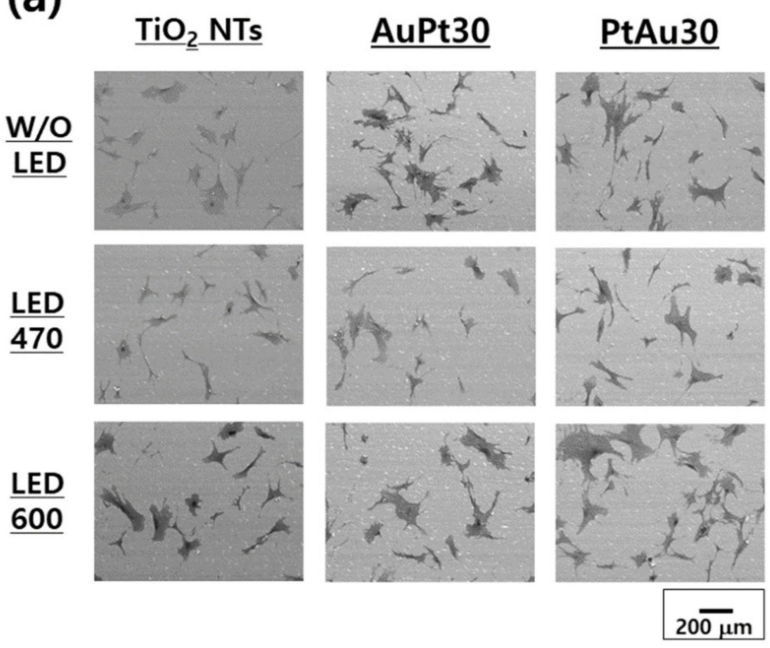

(b)

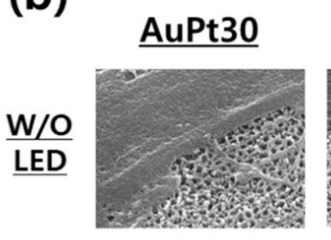

\section{PtAu30}
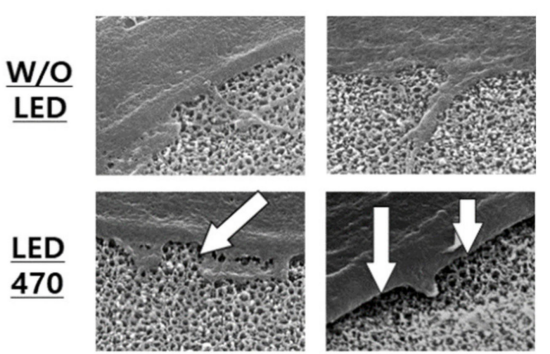

LED
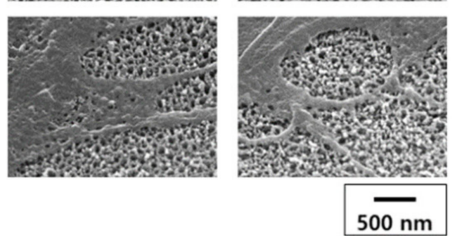

Figure 6. The morphological characterization of hMSCs cultured on $\mathrm{Au}$ and $\mathrm{Pt}$ multi-coated $\mathrm{TiO}_{2}$ nanotubes with and without visible light irradiation (470 and $600 \mathrm{~nm}$ for $30 \mathrm{~min}$ ) was observed by FE-SEM ((a) $100 \times$ and (b) $50,000 \times)$.

\subsubsection{ALP Activity Assay}

In Figure 7, after 1 week of cell culture, the ALP activity of $\mathrm{AuPt}-\mathrm{TiO}_{2}$ nanotubes and $\mathrm{PtAu}-\mathrm{TiO}_{2}$ nanotubes with $600 \mathrm{~nm}$ visible light irradiation was higher than that of the other experimental groups. After 2 weeks of cell culture, the ALP activity was decreased compared to the ALP activity of the first week. In addition, the $600 \mathrm{~nm}$ visible light irradiation still promoted the ALP activity of the experimental groups of $\mathrm{AuPt}-\mathrm{TiO}_{2}$ nanotubes and $\mathrm{PtAu}-\mathrm{TiO}_{2}$ nanotubes.
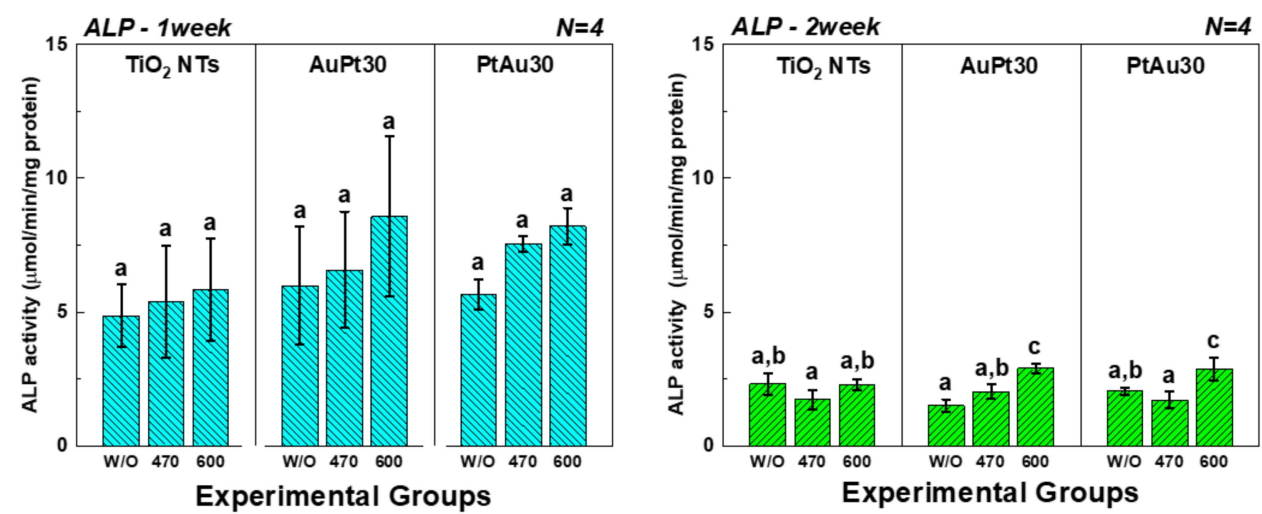

Figure 7. The ALP activity of the hMSCs cultured on $\mathrm{Au}$ and $\mathrm{Pt}$ multi-coated $\mathrm{TiO}_{2}$ nanotubes. In the graph, $\mathrm{W} / \mathrm{O}, 470$, and 600 designate no irradiation, $470 \mathrm{~nm}$ irradiation, and $600 \mathrm{~nm}$ irradiation, respectively. Moreover, in each graph, the values of experimental groups with the same lowercase letter $(\mathrm{a}, \mathrm{b}$, or $\mathrm{c})$ are not statistically different as determined by one-way ANOVA at $\alpha=0.05$.

\subsubsection{Quantitative Real-Time PCR Assay}

The mRNA gene expression of OPN, OCN, and BSP of the hMSCs cultured on Au and $\mathrm{Pt}$ multi-coated $\mathrm{TiO}_{2}$ nanotubes analyzed by quantitative real-time PCR assay is shown in Figure 8. There was no statistical difference in mRNA expression of BSP between the groups. In addition, the mRNA expression of OPN and $\mathrm{OCN}$ of $\mathrm{PtAu}-\mathrm{TiO}_{2}$ nanotubes with 
$600 \mathrm{~nm}$ visible light irradiation showed the highest values among all experimental groups and conditions.
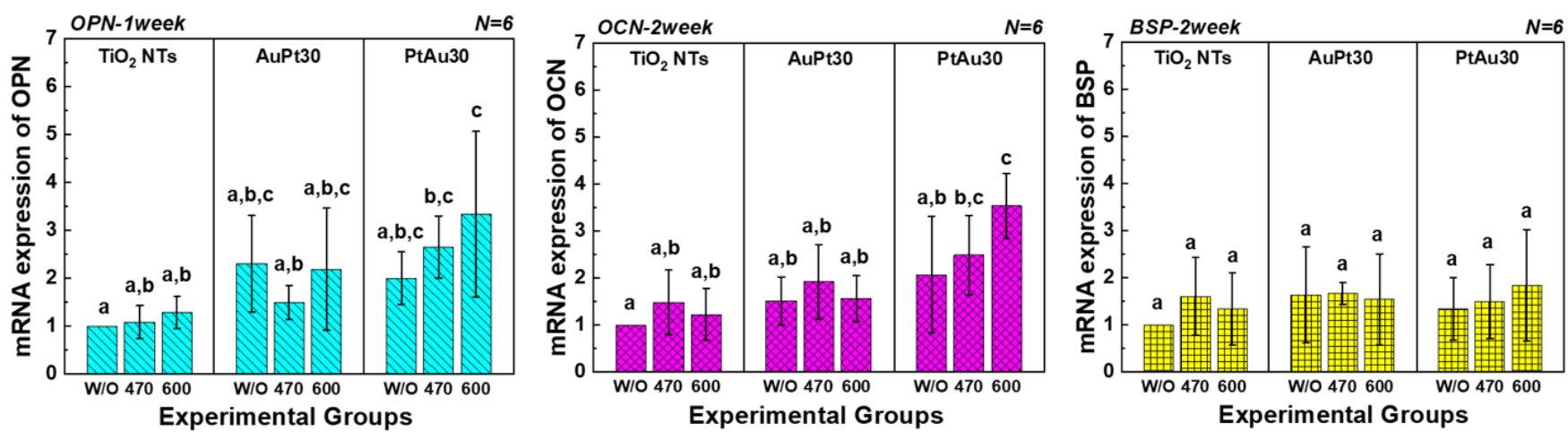

Figure 8. The mRNA expression of OPN, OCN, and BSP of the hMSCs cultured on $\mathrm{Au}$ and Pt multi-coated $\mathrm{TiO}_{2}$ nanotubes analyzed by quantitative real-time PCR assay. In the graph, W/O, 470, and 600 designate no irradiation, $470 \mathrm{~nm}$ irradiation, and $600 \mathrm{~nm}$ irradiation, respectively. Moreover, in each graph, the values of experimental groups with the same lowercase letter $(a, b$, or $c)$ are not statistically different as determined by one-way ANOVA at $\alpha=0.05$.

\subsubsection{Alizarin Red Assay}

The results of the alizarin red assay after 2 and 3 weeks of cell culture are shown in Figure 9. After 2 weeks of cell culture, the alizarin red values of the $\mathrm{PtAu}-\mathrm{TiO}_{2}$ nanotubes were significantly higher than those of $\mathrm{Pt}_{-} \mathrm{TiO}_{2}$ nanotubes with $600 \mathrm{~nm}$ visible light irradiation $(p<0.05)$. In addition, after 3 weeks of cell culture, the alizarin red values of the $\mathrm{PtAu}-\mathrm{TiO}_{2}$ nanotubes were significantly higher than those of $\mathrm{Pt}-\mathrm{TiO}_{2}$ nanotubes on both conditions of the 470 and $600 \mathrm{~nm}$ visible light irradiation $(p<0.05)$.
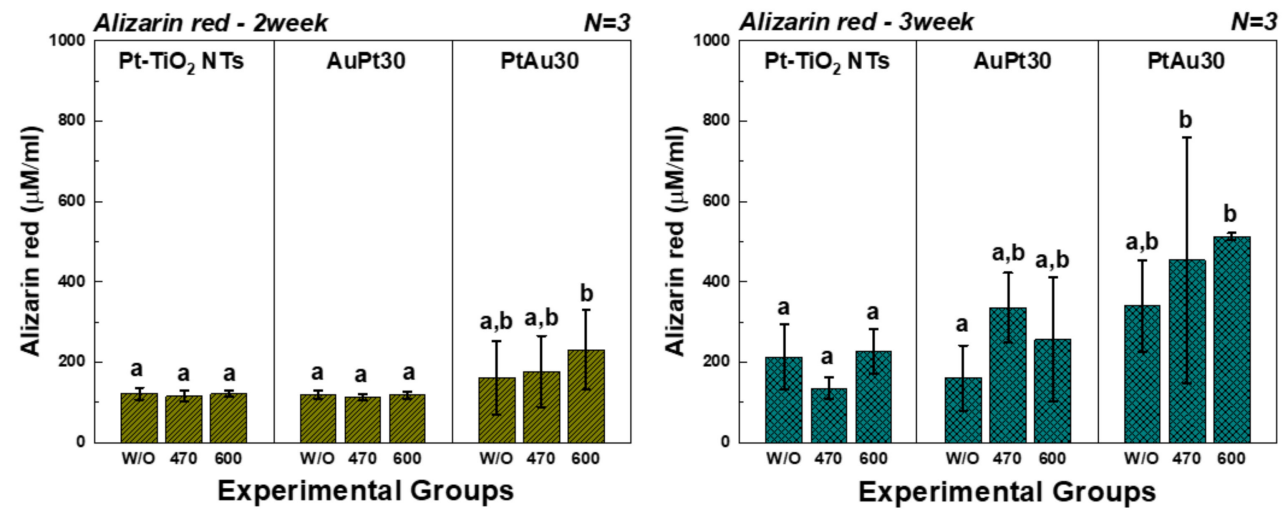

Figure 9. The alizarin red results of hMSCs cultured on $\mathrm{Au}$ and $\mathrm{Pt}$ multi-coated $\mathrm{TiO}_{2}$ nanotubes. In the graph, W/O, 470, and 600 designate no irradiation, $470 \mathrm{~nm}$ irradiation, and $600 \mathrm{~nm}$ irradiation, respectively. Moreover, in each graph, the values of experimental groups with the same lowercase letter $(\mathrm{a}$ or $\mathrm{b}$ ) are not statistically different as determined by one-way ANOVA at $\alpha=0.05$.

\section{Discussion}

The FE-SEM images confirmed that the agglomeration and coarsening of the sputtered nanoparticles were formed at the surface of the $\mathrm{TiO}_{2}$ nanotubes coated with $\mathrm{Au}$ and $\mathrm{Pt}$ for 60 s, respectively. This phenomenon's occurrence with the Au nanoparticles was relatively more frequent than with the Pt nanoparticles due to the differences in the rates of their ion plasma coatings [30]. In addition, from the inset images of Figure 1, the morphology of the nanoparticles changed from round to a rod or crescent shape during the ion plasma coating process.

The diffuse UV-Vis-NIR spectrophotometry confirmed that four major absorbance peaks were detected at 360-380 nm (typical transition of electrons from the valence band to conduction band of anatase $\mathrm{TiO}_{2}$ after UV light irradiation [31]), 420-480 nm (plasmonic 
photocatalysis of $\mathrm{Au}$ and $\mathrm{Pt}$ coated $\mathrm{TiO}_{2}$ [32,33]), 550-650 nm (the short axis photothermal scattering of coated Au and Pt nanoparticles), and 800-950 nm (the long axis photothermal scattering of coated $\mathrm{d} \mathrm{Au}$ and Pt nanoparticles). The wavelength range of four absorbance peaks is related to photothermal scattering and depends on the morphology of the Au and $\mathrm{Pt}$ nanoparticles deposited on the $\mathrm{TiO}_{2}$ nanotubes, as observed by FE-SEM images [34-37]. Moreover, there was no change in the range of the four major absorption wavelengths with the different $\mathrm{Au}$ and $\mathrm{Pt}$ coating periods.

The TEM and elementary mapping images confirmed that most of the second-coated nanoparticles were distributed on the top layer of the nanotubes. In addition, the amount of coated Au was 2-3 times higher than the amount of coated Pt. These results showed a similar trend as those from the FE-SEM observations and EDX analysis.

The XPS analysis confirmed that Ti $2 \mathrm{p}$ and $\mathrm{O}$ 1s peaks of $\mathrm{Au}$ and $\mathrm{Pt}$ multi-coated $\mathrm{TiO}_{2}$ nanotubes moved to lower energies compared to those of uncoated $\mathrm{TiO}_{2}$ nanotubes. This result means that the amounts of $\mathrm{Ti}$ and $\mathrm{O}$ species were decreased at the surface of the $\mathrm{TiO}_{2}$ nanotubes after $\mathrm{Au}$ and Pt coating [38,39]. In addition, the Pt $4 \mathrm{f}$ XPS spectra of $\mathrm{PtAu}-\mathrm{TiO}_{2}$ nanotubes showed three peaks compared to those of $\mathrm{Au}-\mathrm{Pt} \mathrm{TiO}_{2}$ nanotubes having two peaks. This phenomenon is related to the amount of Pt deposited directly on the $\mathrm{TiO}_{2}$ nanotubes. Because Pt sputtering time was short $(30 \mathrm{~s})$, the small amounts of $\mathrm{Pt}$ nanoparticles were coated on the surface of the $\mathrm{TiO}_{2}$ nanotubes (Figure 1), and these nanoparticles are likely to be easily oxidized to form $\mathrm{PtO}_{\mathbf{X}}$ structures $[28,29]$. Thus, the new binding peak $(\sim 72.5 \mathrm{eV})$ was expected to be the $\mathrm{Pt}-\mathrm{O}$ bond generated by binding Pt metals to the $\mathrm{TiO}_{2}$ nanotubes in a short time.

The antibacterial activity test confirmed that the antibacterial effects were generated by irradiation with visible light at 470 and $600 \mathrm{~nm}$ in both the $\mathrm{AuPt}-\mathrm{TiO}_{2}$ nanotubes and $\mathrm{PtAu}-\mathrm{TiO}_{2}$ nanotubes experimental groups. This phenomenon is presumed to be due to the expansion of the plasmonic photocatalyst and the shape change in the $\mathrm{Au}$ and $\mathrm{Pt}$ nanoparticles, showing a similar tendency to the results that were identified in a previous study [24]. Other studies reported that plasmonic photocatalysis of the $\mathrm{Au}-\mathrm{TiO}_{2}$ combination occurred under the irradiation of visible light above $550 \mathrm{~nm}$ and near-infrared light according to the change in size and shape of the Au nanoparticles bonded to the $\mathrm{TiO}_{2}[40,41]$. Therefore, it is reasonable that the antibacterial effect of the plasmonic photocatalyst is improved not only at 470 but also at $600 \mathrm{~nm}$ due to the various shapes of the fine nanoparticles [42].

In terms of initial cell attachment and proliferation of hMSCs cultured on various experimental specimens, we pre-tested the MTT assay. The MTT assay confirmed that the cell attachment and proliferation of hMSCs cultured on all experimental groups are similar to the values of the control group (data are not shown).

The real-time PCR assay confirmed the highest mRNA expression values of OPN and OCN of $\mathrm{PtAu}-\mathrm{TiO}_{2}$ nanotubes with the $600 \mathrm{~nm}$ visible light irradiation. Therefore, the osteogenic functionality of hMSCs was strongly related to (1) the wavelength of visible light irradiation and (2) the stack order of the Au and Pt coating. To better understand the correlation between the wavelength of visible light and osteogenic differentiation, we investigated the morphologies of the hMSCs cultured on the surface of the experimental specimens by FE-SEM. When the hMSCs were irradiated with $600 \mathrm{~nm}$ visible light, the spread of hMSCs and the number of filopodia were increased (Figure 6a). The poor attachment of the hMSCs to the surface of the specimen under 470 visible light irradiation was also strongly related to the cell proliferation and differentiation (Figure 6b). The lowlevel laser therapy (LLLT) effect in the region of 600-1000 nm, which plays a critical role in wound healing, tissue repair, and inflammation relief [43-46], is expected to have had a significant effect on the promoted osteogenic functionality in hMSCs. Therefore, $600 \mathrm{~nm}$ visible light irradiation is expected to induce the synergic effect of antibacterial activity and the osteogenic differentiation of hMSCs.

Contrary to our previous study [24], in terms of the correlation between the stack order of $\mathrm{Au}$ and $\mathrm{Pt}$ and osteogenic functionality, the experimental group in which Au was coated 
on the uppermost layer showed excellent osteogenic differentiation in this study. In general, $\mathrm{Pt}$ has been proven to prevent the electron recombination of the $\mathrm{Au}-\mathrm{TiO}_{2}$ surface which promotes the plasmonic photocatalytic effect $[25,26]$, but there are no studies on the effects of osteogenic differentiation performance in hMSCs. Several previous studies have found that the size and shape changes of Au nanoparticles strongly affect osseointegration [47-49]. Thus, it can be conjectured that shorter sputtering times resulted in a coating of finer nanoparticles. Finer $\mathrm{Au}$ and $\mathrm{Pt}$ nanoparticles stacked on $\mathrm{TiO}_{2}$ nanotubes are expected to conduct different levels of osteogenic acceleration when compared to our previous research. Further investigations will be required to investigate this phenomenon.

The alizarin red assay was performed to compare the osteogenic performance of this experimental condition (multi-coating) and the previous experimental condition (single coating). The PtAu- $\mathrm{TiO}_{2}$ nanotubes under visible light irradiation showed higher alizarin red values when compared to the $\mathrm{Pt}-\mathrm{TiO}_{2}$ nanotubes, which showed the highest osteogenic performance in a previous study $(p<0.05)$. Therefore, the multi-coating is expected to show better osteogenic performance than a single coating.

\section{Conclusions}

Within the limitation of this study, we have confirmed through this investigation that $\mathrm{Au}$ and $\mathrm{Pt}$ multi-coatings on $\mathrm{TiO}_{2}$ nanotubes have excellent antibacterial activities when exposed to 470 and $600 \mathrm{~nm}$ visible light irradiation. This was found to be a result of plasmonic photocatalysis due to the LSPR effect of the Au and Pt nanoparticles. Moreover, the alizarin red assay showed that the multi-coating of $\mathrm{Au}$ and $\mathrm{Pt}$ is expected to improve osteogenic differentiation of hMSCs compared to the single coating of Pt. Therefore, we concluded that the $\mathrm{TiO}_{2}$ nanotubes multi-coated with $\mathrm{Au}$ and Pt can extend the limited UV antibacterial effect of $\mathrm{TiO}_{2}$ nanotubes into the visible light region (up to $600 \mathrm{~nm}$ ) to improve the osteogenic performance. In addition, this novel multi-combination of noble metal nanoparticles is expected to become a base technology for the development of new surface treatment technologies for implantable devices.

Author Contributions: K.-S.M. and Y.-B.P. equally contributed to this study. Conceptualization, E.J.C. and S.-H.O.; methodology, E.-J.C. and S.-H.O.; formal analysis, J.-M.B. and S.-H.O.; investigation, K.-S.M. and Y.-B.P.; writing—original draft preparation, S.-H.O.; writing—review and editing, Y.-B.P., E.-J.C. and J.-M.B.; supervision, S.-H.O.; project administration, S.-H.O.; funding acquisition, S.-H.O. All authors have read and agreed to the published version of the manuscript.

Funding: This work was supported by the National Research Foundation of Korea (NRF) (Grant No. 2019R1A2C1003249) which is funded by the Korea government (MSIT).

Institutional Review Board Statement: Not applicable.

Informed Consent Statement: Not applicable.

Data Availability Statement: Not applicable.

Conflicts of Interest: The authors declare no conflict of interest.

\section{References}

1. Karthik, K.; Sivakumar, S.; Thangaswamy, V. Evaluation of implant success: A review of past and present concepts. J. Pharm. Bioall. Sci. 2013, 5, S117-S119. [CrossRef]

2. Papaspyridakos, P.; Chen, C.J.; Singh, M.; Weber, H.P.; Gallucci, G.O. Success criteria in implant dentistry: A systematic review. J. Dent. Res. 2012, 91, 242-248. [CrossRef]

3. Esposito, M.; Thomsen, P.; Ericson, L.E.; Lekholm, U. Histopathologic observations on early oral implant failures. Int. J. Oral. Maxillofac. Implants 1999, 14, 798-810.

4. Kenawy, E.R.; Worley, S.D.; Broughton, R. The chemistry and applications of antimicrobial polymers: A state-of-the-art review. Biomacromolecules 2007, 8, 1359-1384. [CrossRef]

5. Veerapandian, M.; Yun, K. Functionalization of biomolecules on nanoparticles: Specialized for antibacterial applications. Appl. Microbiol. Biotechnol. 2011, 90, 1655-1667. [CrossRef]

6. Rezazadeh, N.H.; Buazar, F.; Matroodi, S. Synergistic effects of combinatorial chitosan and polyphenol biomolecules on enhanced antibacterial activity of biofunctionalized silver nanoparticles. Sci. Rep. 2020, 10, 19615. [CrossRef] 
7. Wang, L.; Hu, C.; Shao, L. The antimicrobial activity of nanoparticles: Present situation and prospects for the future. Int. J. Nanomed. 2017, 12, 1227-1249. [CrossRef]

8. Hajipour, M.J.; Fromm, K.M.; Ashkarran, A.A.; Jimenez de Aberasturi, D.; de Larramendi, I.R.; Rojo, T.; Serpooshan, V.; Parak, W.J.; Mahmoudi, M. Antibacterial properties of nanoparticles. Trends Biotechnol. 2012, 30, 499-511. [CrossRef]

9. $\mathrm{Mu}$, H.B.; Tang, J.J.; Liu, Q.J.; Sun, C.L.; Wang, T.T.; Duan, J.Y. Potent antibacterial nanoparticles against biofilm and intracellular bacteria. Sci. Rep. 2016, 6, 18877. [CrossRef]

10. Liu, Y.; Qin, R.; Zaat, S.A.J.; Breukink, E.; Heger, M. Antibacterial photodynamic therapy: Overview of a promising approach to fight antibiotic-resistant bacterial infections. J. Clin. Transl. Res. 2015, 1, 140-167.

11. Goncalves, N.L.; Borges, V.M.; de Arruda, J.A.A.; Dos Santos, E.G.; Diniz, I.M.A.; Madeira, M.F.M.; Moreno, A. Antimicrobial effects of photodynamic therapy on Staphylococcus aureus biofilm grown on a specific acrylic resin surface for ocular prostheses. Photodiagn. Photodyn. Ther. 2020, 32, 102042. [CrossRef]

12. Hokari, T.; Morozumi, T.; Komatsu, Y.; Shimizu, T.; Yoshino, T.; Tanaka, M.; Tanaka, Y.; Nohno, K.; Kubota, T.; Yoshie, H. Effects of antimicrobial photodynamic therapy and local administration of minocycline on clinical, microbiological, and inflammatory markers of periodontal pockets: A pilot study. Int. J. Dent. 2018, 2018, 1748584. [CrossRef]

13. Cai, Y.; Stromme, M.; Melhus, A.; Engqvist, H.; Welch, K. Photocatalytic inactivation of biofilms on bioactive dental adhesives. J. Biomed. Mater. Res. B Appl. Biomater. 2014, 102, 62-67. [CrossRef]

14. Rupp, F.; Haupt, M.; Eichler, M.; Doering, C.; Klostermann, H.; Scheideler, L.; Lachmann, S.; Oehr, C.; Wendel, H.P.; Decker, E.; et al. Formation and photocatalytic decomposition of a pellicle on anatase surfaces. J. Dent. Res. 2012, 91, 104-109. [CrossRef]

15. Wu, H.; Xie, L.; He, M.; Zhang, R.T.; Tian, Y.; Liu, S.R.; Gong, T.; Huo, F.J.; Yang, T.; Zhang, Q.Y.; et al. A wear-resistant TiO 2 nanoceramic coating on titanium implants for visible-light photocatalytic removal of organic residues. Acta Biomater. 2019, 97, 597-607. [CrossRef]

16. Nagay, B.E.; Dini, C.; Cordeiro, J.M.; Ricomini-Filho, A.P.; de Avila, E.D.; Rangel, E.C.; da Cruz, N.C.; Barao, V.A.R. Visiblelight-induced photocatalytic and antibacterial activity of $\mathrm{TiO}_{2}$ codoped with nitrogen and bismuth: New perspectives to control implant-biofilm-related diseases. ACS Appl. Mater. Interfaces 2019, 11, 18186-18202. [CrossRef] [PubMed]

17. Gyorgyey, A.; Janovak, L.; Adam, A.; Kopniczky, J.; Toth, K.L.; Deak, A.; Panayotov, I.; Cuisinier, F.; Dekany, I.; Turzo, K Investigation of the in vitro photocatalytic antibacterial activity of nanocrystalline $\mathrm{TiO}_{2}$ and coupled $\mathrm{TiO}_{2} / \mathrm{Ag}$ containing copolymer on the surface of medical grade titanium. J. Biomater. Appl. 2016, 31, 55-67. [CrossRef] [PubMed]

18. Xia, S.M.; Zhang, Y.Q.; Zheng, Y.F.; Xu, C.S.; Liu, G.M. Enhanced visible light photocatalytic activity of N, F-codoped TiO 2 powders with high thermal stability. Environ. Technol. 2019, 40, 1418-1424. [CrossRef] [PubMed]

19. Fu, A.; Chen, X.; Tong, L.; Wang, D.; Liu, L.; Ye, J. Remarkable visible-light photocatalytic activity enhancement over Au/p-type $\mathrm{TiO}_{2}$ promoted by efficient interfacial charge transfer. ACS Appl. Mater. Interfaces 2019, 11, 24154-24163. [CrossRef]

20. Qin, L.; Wang, G.; Tan, Y. Plasmonic Pt nanoparticles- $\mathrm{TiO}_{2}$ hierarchical nano-architecture as a visible light photocatalyst for water splitting. Sci. Rep. 2018, 8, 16198. [CrossRef]

21. Ueda, T.; Ueda, K.; Ito, K.; Ogasawara, K.; Kanetaka, H.; Mokudai, T.; Niwano, Y.; Narushima, T. Visible-light-responsive antibacterial activity of $\mathrm{Au}$-incorporated $\mathrm{TiO}_{2}$ layers formed on $\mathrm{Ti}-(0-10)$ at $\%$ Au alloys by air oxidation. J. Biomed. Mater. Res. A 2019, 107, 991-1000. [CrossRef] [PubMed]

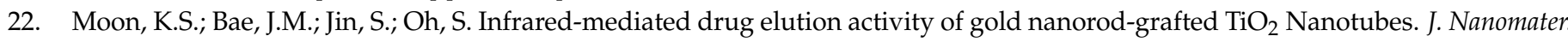
2014, 2014, 750813. [CrossRef]

23. Moon, K.S.; Park, Y.B.; Bae, J.M.; Oh, S. Near-infrared laser-mediated drug release and antibacterial activity of gold nanorodsputtered titania nanotubes. J. Tissue Eng. 2018, 9, 1-9. [CrossRef]

24. Moon, K.S.; Choi, E.J.; Bae, J.M.; Park, Y.B.; Oh, S. Visible light-enhanced antibacterial and osteogenic functionality of Au and Pt nanoparticles deposited on $\mathrm{TiO}_{2}$ nanotubes. Materials 2020, 13, 3721. [CrossRef] [PubMed]

25. Li, J.J.; Zhu, B.L.; Wang, G.C.; Liu, Z.F.; Huang, W.P.; Zhang, S.M. Enhanced CO catalytic oxidation over an Au-Pt alloy supported on $\mathrm{TiO}_{2}$ nanotubes: Investigation of the hydroxyl and Au/Pt ratio influences. Catal. Sci. Technol. 2018, 8, 6109-6122. [CrossRef]

26. Ataee-Esfahani, H.; Wang, L.; Nemoto, Y.; Yamauchi, Y. Synthesis of bimetallic Au@ Pt nanoparticles with Au core and nanostructured Pt shell toward highly active electrocatalysts. Chem. Mater. 2010, 22, 6310-6318. [CrossRef]

27. Li, J.; Zhou, H.; Qian, S.; Liu, Z.; Feng, J.; Jin, P.; Liu, X. Plasmonic gold nanoparticles modified titania nanotubes for antibacterial application. Appl. Phys. Lett. 2014, 104, 261110. [CrossRef]

28. Kibis, L.S.; Svintsitskiy, D.A.; Stadnichenko, A.I.; Slavinskaya, E.M.; Romanenko, A.V.; Fedorova, E.A.; Stonkus, O.A.; Svetlichnyi, V.A.; Fakhrutdinova, E.D.; Vorokhta, M.; et al. In situ probing of $\mathrm{Pt} / \mathrm{TiO}_{2}$ activity in low-temperature ammonia oxidation. Catal. Sci. Technol. 2021, 11, 250-263. [CrossRef]

29. Parkinson, C.R.; Walker, M.; McConville, C.F. Reaction of atomic oxygen with a Pt(111) surface: Chemical and structural determination using XPS, CAICISS and LEED. Surf. Sci. 2003, 545, 19-33. [CrossRef]

30. Rod, H.; Sina, S.; John, Y.; Partrick, C. Target material selection for sputter coating of SEM samples. Micros. Today 2019, 27, 32-36.

31. Gu, D.; Wang, Y.; Li, Z.D.; Liu, Y.; Wang, B.H.; Wu, H.J. UV-light aided photoelectrochemical synthesis of Au/TiO 2 NTs for photoelectrocatalytic degradation of HPAM. RSC Adv. 2016, 6, 63711-63716. [CrossRef]

32. Yoo, S.M.; Rawal, S.B.; Lee, J.E.; Kim, J.; Ryu, H.Y.; Park, D.W.; Lee, W.I. Size-dependence of plasmonic Au nanoparticles in photocatalytic behavior of $\mathrm{Au} / \mathrm{TiO}_{2}$ and $\mathrm{Au} @ \mathrm{SiO}_{2} / \mathrm{TiO}_{2}$. Appl. Catal. A-Gen. 2015, 499, 47-54. [CrossRef] 
33. Lin, Z.J.; Wang, X.H.; Liu, J.; Tian, Z.Y.; Dai, L.C.; He, B.B.; Han, C.; Wu, Y.G.; Zeng, Z.G.; Hu, Z.Y. On the role of localized surface plasmon resonance in UV-Vis light irradiated $\mathrm{Au} / \mathrm{TiO}_{2}$ photocatalysis systems: Pros and cons. Nanoscale 2015, 7, $4114-4123$. [CrossRef]

34. Chen, Y.S.; Frey, W.; Kim, S.; Homan, K.; Kruizinga, P.; Sokolov, K.; Emelianov, S. Enhanced thermal stability of silica-coated gold nanorods for photoacoustic imaging and image-guided therapy. Opt. Express 2010, 18, 8867-8878. [CrossRef] [PubMed]

35. Khlebtsov, B.N.; Khlebtsov, N.G. Multipole plasmons in metal nanorods: Scaling properties and dependence on particle size, shape, orientation, and dielectric environment. J. Phys. Chem. C 2007, 111, 11516-11527. [CrossRef]

36. Liao, Q.; Mu, C.; Xu, D.S.; Ai, X.C.; Yao, J.N.; Zhang, J.P. Gold nanorod arrays with good reproducibility for high-performance surface-enhanced raman scattering. Langmuir 2009, 25, 4708-4714. [CrossRef]

37. Zhang, K.; Xiang, Y.; Wu, X.; Feng, L.; He, W.; Liu, J.; Zhou, W.; Xie, S. Enhanced optical responses of Au@Pd core/shell nanobars. Langmuir 2009, 25, 1162-1168. [CrossRef]

38. Nagasawa, Y.; Choso, T.; Karasuda, T.; Shimomura, S.; Ouyang, F.; Tabata, K.; Yamaguchi, Y. Photoemission study of the interaction of a reduced thin film $\mathrm{SnO}_{2}$ with oxygen. Surf. Sci. 1999, 433-435, 226-229. [CrossRef]

39. Vuong, N.M.; Kim, D.; Kim, H. Porous Au-embedded $\mathrm{WO}_{3}$ nanowire structure for efficient detection of $\mathrm{CH}_{4}$ and $\mathrm{H}_{2} \mathrm{~S}$. Sci. Rep 2015, 5, 11040. [CrossRef]

40. Nishijima, Y.; Ueno, K.; Kotake, Y.; Murakoshi, K.; Inoue, H.; Misawa, H. Near-infrared plasmon-assisted water oxidation. J. Phys. Chem. Lett. 2012, 3, 1248-1252. [CrossRef]

41. Yuzawa, H.; Yoshida, T.; Yoshida, H. Gold nanoparticles on titanium oxide effective for photocatalytic hydrogen formation under visible light. Appl. Catal. B-Environ. 2012, 115, 294-302. [CrossRef]

42. Tanaka, A.; Hashimoto, K.; Kominami, H. A very simple method for the preparation of $\mathrm{Au} / \mathrm{TiO}_{2}$ plasmonic photocatalysts working under irradiation of visible light in the range of 600-700 nm. Chem. Commun. 2017, 53, 4759-4762. [CrossRef]

43. Sutherland, J.C. Biological effects of polychromatic light. Photochem. Photobiol. 2002, 76, 164-170. [CrossRef]

44. Kim, W.S.; Calderhead, R.G. Is light-emitting diode phototherapy (LED-LLLT) really effective? Laser Thera. 2011, 20, 205-215. [CrossRef]

45. Hopkins, J.T.; McLoda, T.A.; Seegmiller, J.G.; Baxter, G.D. Low-level laser therapy facilitates superficial wound healing in humans: A triple-blind, sham-controlled study. J. Athl. Train. 2004, 39, 223-229.

46. Aimbire, F.; Albertini, R.; Pacheco, M.T.; Castro-Faria-Neto, H.C.; Leonardo, P.S.; Iversen, V.V.; Lopes-Martins, R.A.; Bjordal, J.M. Low-level laser therapy induces dose-dependent reduction of TNF alpha levels in acute inflammation. Photomed. Laser. Surg. 2006, 24, 33-37. [CrossRef]

47. Zhang, Y.H.; Kong, N.; Zhang, Y.C.; Yang, W.R.; Yan, F.H. Size-dependent effects of gold nanoparticles on osteogenic differentiation of human periodontal ligament progenitor cells. Theranostics 2017, 7, 1214-1224. [CrossRef]

48. Ko, W.K.; Kim, S.J.; Heo, D.N.; Han, I.B.; Kim, S.; Kwon, I.K.; Sohn, S. Double layers of gold nanoparticles immobilized titanium implants improve the osseointegration in rabbit models. Nanomed. Nanotechnol. 2020, 24, 102129. [CrossRef]

49. Li, J.C.; Li, J.J.; Zhang, J.; Wang, X.L.; Kawazoe, N.; Chen, G.P. Gold nanoparticle size and shape influence on osteogenesis of mesenchymal stem cells. Nanoscale 2016, 8, 7992-8007. [CrossRef] 